Research Trainee

\title{
Addressing Institutional Racism Against Aboriginal and Torres Strait Islanders of Australia in Mainstream Health Services: Insights From Aboriginal Community Controlled Health Services
}

\author{
Anna Socha
}

\section{A R T I C L E I N F O}

Keywords:

Racism

Cultural safety

Australia

Indigenous Peoples

https://doi.org/10.32799/ijih.v16i1.33918

A U T H OR IN F O

\begin{abstract}
A B S T R A C T
With long colonial histories, Aboriginal and Torres Strait Islander Peoples in Australia experience lower life expectancy and a higher burden of illness. To this day, Indigenous Peoples experience interpersonal, systemic, and institutional racism in the mainstream public health system of Australia, leading to the underuse of mainstream health services and resulting in many Indigenous Australians living in a state of persistent crisis. Extreme and unacceptable levels of institutional racism have been identified in the hospitals and health services of Queensland, Australia, using the Marrie Institutional Racism Matrix (MIRM), an evidence-based assessment tool for identifying, measuring, and monitoring racism in institutional settings. This paper aims to identify ways to address institutional racism against Indigenous Peoples in the health care sector. Specifically, using publicly available documents, a case study analysis of the Institute for Urban Indigenous Health (IUIH), a network of Aboriginal Community Controlled Health Services, is conducted using the MIRM as a guide. The conclusion is that the IUIH actively works to address institutional racism by (a) including Indigenous people in key decision-making processes and structures; (b) undertaking numerous community engagement strategies; (c) building partnerships within and outside the health sector to address the social determinants of health; and (d) working in ways that align with Indigenous ways of being and doing. It is argued that mainstream health services need to be aware of institutional racism and learn from the approaches of Indigenous-led organizations to create institutions that are inclusive of Indigenous members of society.
\end{abstract}

Anna Socha, MSc, BHSc, McMaster University, Hamilton, Ontario, Canada. Email: sochaam2@gmail.com 


\section{Glossary}

ACCHS: Aboriginal Community Controlled Health Service

HHS: Hospital and health service

IUIH: Institute for Urban Indigenous Health

MIRM: Marrie Institutional Racism Matrix (also referred to as "the Matrix")

SEQ: South East Queensland

QES: Queensland

\section{Acknowledgements}

I would like to thank Ms. Odette Mazel for taking on the role of my advisor and guiding me in this new area of research for me. I have grown and learned tremendously under your support. I am grateful for the insightful comments offered by the anonymous peer reviewers. I would also like to extend thanks to the Global Health faculty at McMaster University for this opportunity. Lastly, I would like to recognize and acknowledge that the land on which McMaster University is located is in the traditional territories of the Mississauga and Haudenosaunee Nations, and is within the lands protected by the "Dish with One Spoon" wampum agreement. This is stolen land with a colonial past and present, like the lands of the Indigenous Australians described in this paper.

\section{Introduction}

Across the globe and even in the wealthiest of nations, the health status of Indigenous populations remains conspicuously poor, despite great strides in improving population health on a global scale. The significant gains and advantages that development has provided Australia and other developed countries is not reflected in Indigenous communities (Jackson Pulver et al., 2010). Aboriginal and Torres Strait Islander Peoples are the First Peoples of Australia, with Aboriginal people living and thriving on the continent for at least 50,000 to 70,000 years (Hudjashov et al., 2007). An estimated half a million Indigenous people currently live in Australia, comprising $2.4 \%$ of the Australian population - a population level much below presettlement levels (Madden \& Jackson Pulver, 2009; Reynolds 1989; Saggers \& Gray, 1991). In pre-colonial times, Indigenous Peoples enjoyed much higher standards of living (Paradies, 2016) without suffering inflicted through war, displacement, forced labour, removal of children, relocation, ecological destruction, (un)intentional spread of deadly diseases, banning of Indigenous languages, regulation of marriage, assimilation, and eradication of social, cultural, and spiritual practices (Evans-Campbell, 2008; Glenn, 2015). Colonization and post-colonization over the past 232 years have devastated Aboriginal and Torres Strait Islander Peoples and their cultures.

\footnotetext{
${ }^{1}$ Throughout this article, the terms "Indigenous" and "Aboriginal and Torres Strait Islander" are respectfully used to refer to the First Peoples of Australia.
} 
European settlement in Australia led to a monstrous loss of life, with disease and fatalities leading to fragmentation of Indigenous society (Australians Together, 2020). Government policies aiming to assimilate Aboriginal and Torres Strait Islander Peoples included the confinement of Aboriginal people on mission settlements, dispossession from ancestral land (also known as "country"); and widespread forced removal of Aboriginal and Torres Strait Islander children (often referred to as the Stolen Generations) (Human Rights and Equal Opportunity Commission, 1997). The brutal legacy of colonization and the resulting trauma are persistent shadows in today's Australian society (Jackson Pulver et al., 2010).

Similar to other First Nations populations around the globe, there exists a persistent state of inequality among Aboriginal and Torres Strait Islander Peoples stemming from a devastating colonial history. In fact, Indigenous Australians are considered the most disadvantaged group in Australian society, facing high rates of unemployment and incarceration, low income, substandard housing, and a high burden of ill health and mortality, with a life expectancy that is seventeen years shorter than that of other Australians in 2008 (Paradies et al., 2008). As a result of the colonial structures maintained in societal and health systems (Paradies, 2016), Indigenous Peoples of Australia are three times more likely to be admitted to hospitals and suffer high rates of risk factors, and are one-third less likely to receive appropriate medical care across all conditions compared to non-Indigenous Australians (Cunningham, 2002; Paradies et al., 2008). Evidence has emerged that the Indigenous Peoples of Australia experience unacceptably high levels of both interpersonal and institutional racism, which negatively impacts their health and wellbeing (Cunningham, 2002; Durey \& Thompson, 2012; Herring et al., 2013; Kelaher et al., 2014; Marrie, 2017; Paradies et al., 2008). Notably, an audit of the levels of institutional racism among mainstream public hospitals and health services (HHSs) in Queensland (QES), Australia, identified very high to extreme levels of institutional racism across all sixteen HHSs evaluated (Marrie, 2017).

Racism as a cause of ill health is an emerging field of scholarship in Australia and globally (Paradies et al., 2008). The Racism and Indigenous Health Symposium, held at the University of Melbourne in 2007, noted a paucity of research in this area and thus developed a research agenda to both advance knowledge of racism against Indigenous Peoples and improve the ability to address racism. The Symposium emphasized that institutional racism is the most widespread form of racism and the largest determinant of inequalities in health, impinging on a range of life domains and influencing other social determinants of Indigenous health, including housing, education, employment, and justice administration (Marrie \& Marrie, 2014; Paradies et al., 2008). Institutional racism is defined as "the formal policies, practices, processes, and conditions that serve to increase power differentials between racial, ethnic, cultural, or religious groups" (Marrie \& Marrie, 2014).

The aim of the research described in this paper was to identify the mechanisms by which Aboriginal Community Controlled Health Services (ACCHSs) in QES address institutional racism in their provision of care to Indigenous Australians. These results were then compared to the state of institutional racism in mainstream HHSs. 


\section{Methods}

In order to investigate the mechanisms by which ACCHSs address institutional racism, an exploratory case study analysis was conducted on the Institute for Urban Indigenous Health (IUIH), a network of four ACCHSs encompassing 20 multidisciplinary primary health clinics (IUIH, n.d.-b; IUIH, n.d.-c) throughout South East Queensland (SEQ). The IUIH leads the planning, development, and delivery of comprehensive primary health care services to Aboriginal and Torres Strait Islander people in SEQ, the largest and fastest-growing Indigenous population in Australia (IUIH, n.d.-d). The institute was chosen based on its achievements in Indigenous health and its unique governance structure and model of care (Nous Group, 2019). It is also situated in QES, where an audit of institutional racism in public HHSs was recently conducted (Marrie, 2017). In the case study analysis of the IUIH, the most recent public documents (annual reports and action plans); website content, including videos; and any external evaluations of the Institute's programs were analyzed. This analysis was conducted during June and July 2019.

The Marrie Institutional Racism Matrix (MIRM), or Matrix, was used as a guiding tool for understanding how to conceptualize institutional racism in the Australian health sector and how to analyze the IUIH. The MIRM is an external, evidence-based assessment tool that provides a framework for identifying, measuring, and monitoring racism in institutional settings by applying five criteria and 13 sub-criteria that focus on areas in which institutional racism is commonly noted or experienced by Aboriginal and Torres Strait Islander people (Bourke et al., 2018; Marrie \& Marrie, 2014). The five criteria of the framework are: (a) inclusion in governance; (b) policy implementation; (c) service delivery; (d) employment; and (e) financial accountability. This practical desktop tool aims to improve transparency, implementation, and accountability regarding Closing the Gap (Closing the Gap in Partnership, n.d), which is a federal policy initiative committed to closing the life expectancy gap between Indigenous and non-Indigenous Australians within a generation (by 2030) (Kelaher et al., 2010).

The concept of cultural safety was used as the theoretical orientation of this work (National Aboriginal and Torres Strait Islander Health Workers Association, 2016; Smye \& Browne, 2002). Cultural safety in a health care setting involves understanding the history of colonial violence and oppression that produces health inequities, and suspending ethnocentric views in favour of respecting alternative worldviews and cultural practices (Australian Human Rights Commission, 2018). An awareness of the power relationship between service providers and clients is an integral component of the concept. The author, a white settler of European ancestry living in Canada, researched and reflected on the policies and practices that recreate the traumas inflicted on Indigenous people and perpetuate neocolonial approaches to health care. Historical colonial policies, present-day biases and stereotypes, health system factors, and Indigenous notions of health and wellbeing are all factors that influence the health of Indigenous people which the author investigated. The stories of Indigenous people served as a starting point for this analysis. Further, as an outsider who is not of Indigenous origins or Australian, the author sought guidance from an Australian scholar who specializes in Indigenous law and policy and health care for Indigenous Peoples in Australia. 
The aim of this research is to bring awareness of institutional racism as a key determinant of health for Indigenous Peoples and to share concrete steps that institutions need to take to address institutional racism against Indigenous Peoples. It is evident that examination of the specific pathways by which colonialism and racism impact the health of Indigenous Peoples is a new area of investigation (Paradies, 2016) that needs further attention and research.

\section{Results}

Using the five criteria and 13 sub-criteria of the Matrix, four themes emerged that demonstrated how the IUIH addresses institutional racism. In the textual analysis of public documents, the approach, activities, and policies of the IUIH were categorized within the five criteria and 13 sub-criteria of the Matrix. The sub-criteria containing adequate information to make an assessment, and those that were applicable to Indigenous-led organizations, were used to develop the four core themes: (a) Indigenous Peoples in governance, (b) community engagement, (c) addressing the social determinants of health and building partnerships, and (d) grounding work in traditional Indigenous ways of being and doing.

\section{Indigenous Peoples in Governance}

All board members of the IUIH had expertise in Indigenous health or were actively chairing Indigenous-led organizations, though it was not explicitly stated whether the members were Indigenous themselves (IUIH, n.d.-a). However, the composition of governance bodies across all ACCHSs in Australia shows Indigenous representation, and the majority of boards consisted of all Indigenous people. Specifically, the Healthy Futures Aboriginal Community Controlled Health Services Report Card 2016 reports that of the 134 (97\%) ACCHSs that had a board, most $(86 \%)$ reported governance structures entirely controlled by Aboriginal or Torres Strait Islander people, whereas only 19 services had some non-Indigenous Australians on their boards (Australian Institute of Health and Welfare, 2016). In all, it appears that the board composition of the IUIH and of all ACCHSs reflects their mandate to be Indigenous-led, and they therefore include Indigenous people in decision-making processes.

\section{Community Engagement}

The System of Care model, a unique systemic approach to community-controlled health delivery developed by the IUIH, incorporates community engagement and empowerment (Deadly Choices, 2018). It engages with the community through "community days" and through its Deadly Choices program. Deadly Choices is a school- and community-based chronic disease prevention and education initiative that encourages Aboriginal and Torres Strait Islander people in SEQ to make healthy choices with a specific focus on chronic diseases and their risk factors, such as nutrition, physical activity, and harmful substances. Through a school-based health education program, community-group program, and community events, Deadly Choices not only facilitates community engagement with local health services, but also improves participants' health literacy regarding risk factors and provides an opportunity for social connection (Malseed, 2013). Furthermore, the Yarn It Up Community Engagement Project, led by the IUIH, takes 
IUIH staff out to connect with community members to determine their needs and how the IUIH can best address them (Deadly Choices, 2018). These initiatives demonstrate that the IUIH works closely with the community it serves in various ways and uses this engagement to tailor its programs to effectively address the needs of the community.

\section{Addressing the Social Determinants of Health and Building Partnerships}

The IUIH recognizes the less tangible social factors that can contribute to ill health, such as violence, stress, social exclusion, racism, discrimination, lack of employment, lack of education, and lack of adequate housing (Deadly Choices, 2018). The Institute addresses these underlying social determinants of health through various programs, such as targeted initiatives for families dealing with legal challenges. Notably, the IUIH conducts legal advocacy and support work for family law, domestic violence, elder abuse, tenancy, and civil matters; provides support within the correctional system for Indigenous prisoners; and delivers child safety and family wellbeing services to support vulnerable families, including children at risk of residential care and child protection orders (Nous Group, 2019). Moreover, through its workforce development programs the IUIH is able to equip a large number of Indigenous people with jobs, income, and skills for delivering culturally safe care (Nous Group, 2019). Notably, the IUIH and its four ACCHS member organizations are now the largest employers of Aboriginal and Torres Strait Islander people in SEQ, addressing a key social determinant of health (IUIH, 2019). Lastly, the IUIH provides educational and disability support, as well as means for social participation and cultural connection (Nous Group, 2019).

The IUIH has been commended for its partnerships with the mainstream tertiary education sector and with the government at both the state and Commonwealth levels (Nous Group, 2019). The Institute's ongoing engagement with the mainstream education sector has led to substantial benefits in terms of workforce development among Aboriginal and Torres Strait Islander Peoples. Specific initiatives include the development and implementation of its own executive development program to support Indigenous people entering leadership roles within the IUIH. The Institute also supports school-based and full-time traineeships to promote and enable young Aboriginal and Torres Strait Islander people to enter the health and broader community services workforce. The Ready for Work Program provides opportunities for longterm unemployed Aboriginal and Torres Strait Islander people to work within the Institute (IUIH, 2019).

\section{Grounding their work in traditional Indigenous ways of being and doing}

At the heart of the IUIH is its grounding in Indigenous culture, Indigenous empowerment, and self-determination. The IUIH's model uses traditional ways of being, doing, and belonging used for thousands of years by Aboriginal tribes and Nations across SEQ. Specifically, its Cultural Integrity Investment Framework, known as "The Ways," is a multifaceted approach that aims to build a system wherein Aboriginal terms of reference are privileged (IUIH, 2019; Nous Group; 2019). In line with the Indigenous understanding of health as wholistic, the IUIH provides a wide range of health services including primary health care, 
eye and dental health, social health, women's health, and various allied health services, including occupational therapy, audiology, and dietary health (IUIH, n.d.-e; IUIH, n.d.-f; IUIH, n.d.-g), undertaking a comprehensive approach to health. Further, the IUIH takes a systems-level approach to the health of Indigenous Australians and has created a highly integrated regional health ecosystem by developing partnerships with a wide range of service providers in health (Nous Group, 2019). The Institute is working closely with Queensland Health (the state government body), ACCHS clinics, mainstream general practices, and community-based social health and other support services to ensure appropriate care throughout the health care system (IUIH, n.d.-h; IUIH, n.d.-i; IUIH, n.d.-j; Nous Group, 2019).

\section{Limitations}

Limitations of this research include the significant use of data published by the IUIH, which may include bias given the potential desire to appear favourably in its public reports and website. However, data for the case study was also pulled from external evaluations of IUIH initiatives, presenting less biased information from third-party sources. Further, the limited number of publications from and limited amount of information on the Institute prevented an assessment of all criteria in the Matrix. Interviews and focus groups with Indigenous patients who attend the IUIH would have provided important information on their experiences using the programs and health services to understand the quality of care. However, this research project was limited in scope, time, and resources.

\section{Discussion}

The IUIH actively works to address institutional racism through: (a) Indigenous-led governance; (b) undertaking numerous community engagement strategies; (c) building partnerships within and outside the health sector to address the social determinants of health; and (d) working in ways that align with Indigenous ways of being and doing. In this section, the importance of these four themes is discussed and the IUIH's standing is compared with the results of an audit of institutional racism within public HHSs in QES (Marrie, 2017). The stark contrast demonstrates the urgent need to advance efforts on these four areas of institutional racism within mainstream health services.

Exclusion from governance structures is a key indication of institutional racism, as direct involvement of Indigenous Peoples in the design, planning, and delivery of health care services to their communities is necessary for achieving the best health outcomes, and is a federal policy directive in Australia. Failure to include Indigenous Peoples will compromise access to and delivery of these services, the cultural and clinical safety of health care provision, and, thus, the effectiveness of initiatives aiming to close the gap on Indigenous health outcomes (Marrie \& Marrie, 2014). However, in regards to the inclusion of Indigenous people in the governance of mainstream health services, the results of the QES audit showed that of the 131 board members appointed across all 16 HHSs, only 5 were Aboriginal and/or Torres Strait Islander, and only three HHSs had Indigenous representation (Marrie, 2017). Among the 156 executive positions, 
none were held by an Aboriginal and Torres Strait Islander person (Marrie, 2017). Mainstream HHSs must understand the importance of Indigenous Peoples' involvement in decision-making processes and representation in institutions meant to serve all citizens in QES. Further, they should look to how Indigenous-led organizations are leading on the implementation of workforce and executive development. The inclusion of Indigenous people in decision-making is essential for addressing institutional racism and fully overcoming the legacy of colonization; Indigenous Australians are aware of their unique needs and the direct impacts of racism on their health and health care experiences, and this knowledge is needed for effective health service design, delivery, and implementation. However, it is worth noting that inclusive governance must extend beyond representation and must entirely support Indigenous people in leadership roles.

Community engagement involves shared service planning, partnerships, capacity building, policy development, and quality improvement; however, every health service will have different mechanisms for community engagement (Marrie, 2017). Nonetheless, only five out of 16 HHSs in QES had established Aboriginal and Torres Strait Islander community consultative bodies for the purpose of enabling Aboriginal and Torres Strait Islander people in their region to have direct input and provide feedback regarding the HHS (Marrie, 2017). It is critical that health policies directed to Aboriginal and Torres Strait Islander peoples involve these populations in the design and implementation. Indigenous health outcomes will only change when Aboriginal and Torres Strait Islander Peoples' knowledge, voices, and opinions are able to inform policy, research, and service delivery for Aboriginal people (Zubrzycki et al., 2017). Given that the IUIH had numerous mechanisms for engaging with communities across SEQ, the area with the second-largest Indigenous population in Australia, mainstream services should look to the IUIH as an exemplar of how to engage in a culturally safe manner with Indigenous populations and create services that are inclusive and address community needs.

Collaborative partnerships with other health services and across various sectors to address the social determinants of health and to provide wholistic health care are a clear path toward addressing institutional racism for the IUIH as they align with the Indigenous definition of health and also address the underlying causes of ill health, such as unemployment and low income. In cross-cultural collaboration, power imbalances and institutional racism must also be addressed; for example, research in South Eastern Australia identified that institutional racism often manifests through mainstream organizations dominating partnership processes (Zubrzycki et al., 2017). To achieve effective health care delivery for Indigenous people there must be an integrated and coordinated approach between the public health and Indigenous community controlled health service sectors (Marrie, 2017). The mutual development of joint, local health service plans by mainstream services and ACCHSs has been put forward as a way to reach this goal (Marrie, 2017). The audit of QES HHSs evaluated whether this type of partnership existed in QES. Only one of 16 HHSs had a comprehensive, published plan, while nine of the HHSs provided no evidence of a plan. Six HHSs had entered into agreements or established memoranda of understanding or protocols with local ACCHSs (Marrie, 2017). Increasing collaboration between Indigenous and non-Indigenous people, as well as between Indigenous-led 
and mainstream health services, will be important in addressing the health needs of Indigenous Peoples. Considering that mainstream services continue to be, numerically, the main source of health provision to Indigenous people (Hayman et al., 2009), their action to achieve the Closing the Gap health policy objectives is critical and should involve partnerships with Indigenous-led organizations for knowledge sharing and patient care. Research from South Eastern Australia demonstrated how collaboration between Indigenous and non-Indigenous health workers led to immense professional and personal transformation. Specifically, the non-Aboriginal workers experienced significant transformation as they began to understand the effects of privilege and discrimination in everyday life. As a result, their worldview had changed; many workers began to engage proactively with Aboriginal people in their everyday lives and more readily challenged racism and the effects of privilege (Zubrzycki et al., 2017). Therefore, the benefits of improved collaboration extend beyond the health benefits to Indigenous people.

As alluded to earlier, the IUIH addresses institutional racism through its ability to align itself with the Indigenous definition of health, which focuses on relationships, family, and community, and less on diseases and specific parts of the body (Zubrzycki et al., 2017). Knowledge about Indigenous ways of being and doing, in addition to knowledge of the colonial past and current impacts, is important for non-Indigenous workers. However, the audit assessed the level of cultural competency of the QES HHSs and found that 7 of the 16 HHSs provided no evidence of having established a cultural competency policy, plan, strategy, or program (Marrie, 2017). This was despite significant emphasis by federal and Queensland policies on having a culturally competent workforce and despite the fact that all HHSs (except for one) were specifically funded in their 2013/14-2015/16 health service agreement to provide cultural capability services (Marrie, 2017). Despite cultural competency being only one aspect of cultural safety, these programs are still significantly underdeveloped. Mainstream health services must address institutional racism by working to create culturally safe spaces in their institutions. One way to do this involves education for non-Indigenous health care workers. Approaches that create spaces to welcome Indigenous identities and worldviews can be found in Indigenous-led health institutions, such as IUIH.

Not one of these efforts would be sufficient to address institutional racism on its own. Institutional racism is deeply entrenched in policies and culture, meaning a comprehensive and systems-wide approach is needed to eliminate it. Moreover, the Matrix tool acts as a good measure of what initiatives are being taken to address institutional racism, but it does not measure the quality of these efforts. It is important that Indigenous people are consulted when evaluating institutional racism to understand the quality of services and programs. Future research should work to strengthen this tool and build in dimensions that are able to assess the quality of steps being taken to address institutional racism.

The Australian government has taken a positive step forward by identifying and naming racism as a key social determinant of health for Aboriginal and Torres Strait Islander Peoples and developing a list of actions needed to close the gap in health outcomes between Indigenous and non-Indigenous Australians (Australian Government Department of Health, 2018, 2019). In 
fact, the Implementation Plan for the National Aboriginal and Torres Strait Islander Health Plan 2013-2023, released in 2015, committed the Australian government to developing and promoting the implementation of system levers and accountability mechanisms for addressing racism and discrimination by 2018 (Australian Government Department of Health, 2019). The Australian government must now move these commitments forward and take action to ensure the policies and plans to address institutional racism are implemented in mainstream health services.

\section{Conclusions}

This analysis, guided by the Matrix and cultural safety, concluded that the IUIH actively works to address institutional racism by (a) including Indigenous people in key decision-making processes and structures; (b) engaging with Indigenous communities in numerous ways to identify and address the needs of those communities in spaces that are accessible and convenient; (c) building partnerships within the health sector and with other sectors to address the social determinants of health; and (d) developing an approach that aligns with Indigenous ways of being and doing. In comparison, mainstream health services in QES exhibit very high to extreme levels of institutional racism through lack of inclusion of Indigenous Peoples in governance, lack of community consultative mechanisms, lack of local health plans for building partnerships, and lack of cultural competency programs. The stark contrast between the IUIH and the QES audit on governance structure, community engagement, partnerships, and cultural safety emphasizes the need for mainstream health services to engage with and learn from Indigenous-led organizations to create culturally safe and racism-free institutions. Only by intervening at the institutional level can there be profound and permanent change that is inclusive of Indigenous members of society. The tools and analysis offered in this paper are a contribution to Indigenous health scholarship not only in Australia, but also internationally.

\section{References}

Australian Government Department of Health. (2018). National Aboriginal and Torres Strait Islander Health Plan 2013-2023.

https://www1.health.gov.au/internet/main/publishing.nsf/Content/natsih-plan

Australian Government Department of Health. (2019). Implementation plan for the National Aboriginal and Torres Strait Islander Health Plan 2013-2023. https://www1.health.gov.au/internet/main/publishing.nsf/Content/indigenousimplementation-plan

Australian Human Rights Commission. (2018). Cultural safety for Aboriginal and Torres Strait Islander children and young people: A background paper to inform work on child safe organisations. https://www.humanrights.gov.au/our-work/childrens-rights/child-safeorganisations-and-cultural-safety

Australian Institute of Health and Welfare. (2016). Healthy futures-Aboriginal Community Controlled Health Services: Report card 2016. Cat. no. IHW 171. 
https://www.aihw.gov.au/getmedia/8d2079f7-c3bf-4e5d-840d-

91907a1c86ef/20178.pdf.aspx?inline=true

Australians Together. (2020, November 17). Colonisation: Dispossession, disease and direct conflict. https://australianstogether.org.au/discover/australian-history/colonisation/

Bourke, C. J., Marrie, H., \& Marrie, A. (2018). Transforming institutional racism at an Australian hospital. Australian Health Review, 43(6), 611-618. https://doi.org/10.1071/AH18062

Closing the Gap in Partnership. (n.d). CLOSING THE GAP TARGETS AND OUTCOMES. Retrieved from: https://www.closingthegap.gov.au/targets

Cunningham, J. (2002). Diagnostic and therapeutic procedures among Australian hospital patients identified as Indigenous. Medical Journal of Australia, 176(2), 58-62. https://doi.org/10.5694/j.1326-5377.2002.tb04284.x

Deadly Choices. (2018, October 22). IUIH System of Care [Video]. YouTube. https://www.youtube.com/watch?v=voyx 1CAAa6c \&t $=127 \mathrm{~s}$

Durey, A., \& Thompson, S. C. (2012). Reducing the health disparities of Indigenous Australians: Time to change focus. BMC Health Services Research, 12(1), 151. https://doi.org/10.1186/1472-6963-12-151

Evans-Campbell, T. (2008). Historical trauma in American Indian/Native Alaska communities: A multilevel framework for exploring impacts on individuals, families, and communities. Journal of Interpersonal Violence, 23(3), 316-338. https://doi.org/10.1177\%2F0886260507312290

Glenn, E. N. (2015). Settler colonialism as structure: A framework for comparative studies of U.S. race and gender formation. Sociology of Race and Ethnicity, 1(1), 54-74. Retrieved from: https://journals.sagepub.com/doi/abs/10.1177/2332649214560440

Hayman, N. E., White, N. E., \& Spurling, G. K. (2009). Improving Indigenous patients' access to mainstream health services: The Inala experience. Medical Journal of Australia, 190(10), 604-606. https://doi.org/10.5694/j.1326-5377.2009.tb02581.x

Herring, S., Spangaro, J., Lauw, M., \& McNamara, L. (2013). The intersection of trauma, racism, and cultural competence in effective work with Aboriginal people: Waiting for trust. Australian Social Work, 66(1), 104-117. https://doi.org/10.1080/0312407X.2012.697566

Hudjashov, G., Kivisild, T., Underhill, P. A., Endicott, P., Sanchez, J. J., Lin, A. A., Shen P., Oefner, P., Renfrew, C., Villems, R., \& Forster, P. (2007). Revealing the prehistoric settlement of Australia by Y chromosome and mtDNA analysis. Proceedings of the National Academy of Sciences of the United States of America, 104(21), 8726-8730. https://doi.org/10.1073/pnas.0702928104

Human Rights and Equal Opportunity Commission. (1997). Bringing Them Home: Report of the National Inquiry into the Separation of Aboriginal and Torres Strait Islander Children from Their Families. Sydney: Sterling Press. Retrieved from: https://humanrights.gov.au/our-work/bringing-them-home-report-1997 
Institute for Urban Indigenous Health. (n.d.-a). Meet our Board. https://www.iuih.org.au/aboutiuih/our-board-of-directors/meet-our-board/

Institute for Urban Indigenous Health. (n.d.-b). About IUIH. https://www.iuih.org.au/about-iuih/ Institute for Urban Indigenous Health. (n.d.-c). Our History. https://www.iuih.org.au/aboutiuih/our-history/

Institute for Urban Indigenous Health. (n.d.-d). Welcome to the Institute for Urban Indigenous Health (IUIH) Ltd. https://www.iuih.org.au/

Institute for Urban Indigenous Health. (n.d.-e). Allied Health. http://www.iuih.org.au/Services/Allied_Health

Institute for Urban Indigenous Health. (n.d.-f). Social Health Services. https://www.iuih.org.au/our-services/health-and-wellbeing-services/social-healthservices/

Institute for Urban Indigenous Health. (n.d.-g). Birthing Services. https://www.iuih.org.au/ourservices/health-and-wellbeing-services/child-and-family-services/birthing-in-ourcommunity/

Institute for Urban Indigenous Health. (n.d.-h). Care Coordination. https://www.iuih.org.au/ourservices/care-coordination/

Institute for Urban Indigenous Health. (n.d.-i). Health and Wellbeing Services. https://www.iuih.org.au/our-services/health-and-wellbeing-services/

Institute for Urban Indigenous Health. (n.d.-j). Surgery Pathways. https://www.iuih.org.au/ourservices/health-and-wellbeing-services/surgery-pathways/

Institute for Urban Indigenous Health. (2019). Institute for Urban Indigenous Health: Annual report 2017-18. https://www.iuih.org.au/strategic-documents/annual-reports/iuih-annualreport-2017-18?layout=default

Jackson Pulver, L., Haswell, M. R., Ring, I., Waldon, J., Clark, W., Whetung, V., Kinnon, D., Graham, C., Chino, M., LaValley, J., \& Sadana, R. (2010). Indigenous health - Australia, Canada, Aotearoa New Zealand, and the United States - Laying claim to a future that embraces health for us all (Background Paper 33). World Health Organization. https://www.researchgate.net/publication/281774474_Indigenous_Health__Australia_Canada_Aotearoa_New_Zealand_and_the_United_States__Laying_claim_to_a_future_that_embraces_health_for_us_all

Kelaher, M., Parry, A., Day, S., Paradies, Y., Lawlor, J., \& Solomon, L. (2010). Improving the identification of Aboriginal and Torres Strait Islander People in mainstream general practice. The Lowitja Institute.

https://rsph.anu.edu.au/files/kelaher_indigenous_identification_report_pdf_13237.pdf

Kelaher, M. A., Ferdinand, A. S., \& Paradies, Y. (2014). Experiencing racism in health care: The mental health impacts for Victorian Aboriginal communities. Medical Journal of Australia, 201(1), 44-47. https://doi.org/10.5694/mja13.10503 
Madden R.C, \& Jackson Pulver L.R. (2009). Aboriginal and Torres Strait Islander population: More than reported. Australian Actuarial Journal, 15(2): 181-208. https://www.actuaries.asn.au/library/aaj_vol15_iss2_web.pdf

Malseed, C. (2013). Deadly Choices health promotion initiative evaluation report, January 1December 31, 2013. The Lowitja Institute.

https://www.lowitja.org.au/content/Document/PDF/Deadly-Choices-Evaluation-Reportv2.pdf

Marrie, A. (2017). Addressing institutional barriers to health equity for Aboriginal and Torres Strait Islander People in Queensland's public hospital and health services [Report to Commissioner Kevin Cocks AM, Anti-Discrimination Commission Queensland]. Bukal Consultancy Services.

Marrie, A., \& Marrie, H. (2014). A matrix for identifying, measuring and monitoring institutional racism within public hospitals and health services. Bukal Consultancy Services.

National Aboriginal and Torres Strait Islander Health Workers Association. (2016). Cultural safety framework. https://www.natsihwa.org.au/cultural-safety-framework

Nous Group. (2019). History and performance: Charting the way forward. Independent review of the Institute for Urban Indigenous Health summary report.

https://www.iuih.org.au/nous-review-of-iuih-summary-report-2019/

Paradies, Y. (2016). Colonisation, racism and indigenous health. Journal of Population Research, 33(1), 83-96. https://doi.org/10.1007/s12546-016-9159-y

Paradies, Y., Harris, R., \& Anderson, I. (2008). The impact of racism on Indigenous health in Australia and Aotearoa: Towards a research agenda (Discussion Paper 4). Cooperative Research Centre for Aboriginal Health. https://www.lowitja.org.au/page/services/resources/Cultural-and-socialdeterminants/racism/impact-of-racism-on-indigenous-health

Reynolds, H. (1989). Dispossession: Black Australians and White Invaders. Sydney: Allen \& Unwin. Retrieved from: https://allenandunwin.com/browse/books/generalbooks/history/Dispossession-Henry-Reynolds-9781864481419

Saggers S. \& Gray D. (1991). Policy and practice in Aboriginal health. The Health of Aboriginal Australia, pages 381-420. Ed. J. Reid and P. Trompf. Sydney: Harcourt Brace. Retrieved from: https://trove.nla.gov.au/work/38819300

Smye, V., \& Browne, A. (2002). "Cultural safety" and the analysis of health policy affecting Aboriginal people. Nurse Researcher, 9(3), 42-56. https://doi.org/10.7748/nr2002.04.9.3.42.c6188

Zubrzycki, J., Shipp, R., \& Jones, V. (2017). Knowing, being, and doing: Aboriginal and nonAboriginal collaboration in cancer services. Qualitative Health Research, 27(9), 13161329. https://doi.org/10.1177\%2F1049732316686750 